\section{Apolipoprotein D}

K. J. Lackner ${ }^{1}$ und D. Peetz ${ }^{2}$

${ }^{1}$ Institut für Klinische Chemie und Laboratoriumsmedizin, Universitätsmedizin Mainz, Mainz, Deutschland

${ }^{2}$ Institut für Labormedizin, Helios Klinikum Berlin-Buch,

Berlin, Deutschland

Synonym(e) ApoD

Englischer Begriff apolipoprotein D

Definition ApoD ist ein Apolipoprotein der High Density Lipoproteine (s. $>$ High Density Lipoprotein).
Beschreibung ApoD ist ein ca. 19 kDa schweres Glykoprotein, das zur Familie der $>$ Lipocaline gehört und als 189 Aminosäuren langes Proprotein in verschiedenen Organen einschließlich Leber, Dünndarm, Gehirn und Plazenta synthetisiert wird. Im Plasma ist es zu etwa zwei Dritteln an HDL gebunden. Bildet Disulfidheterodimere mit $>$ Apolipoprotein A-II. ApoD bindet Bilin und eine Reihe anderer kleiner Moleküle; möglicherweise Radikalfänger. Die genaue Funktion ist nicht geklärt. ApoD wird von verschiedenen Tumoren produziert. Eine Rolle in der zerebralen Lipidhomöostase wird postuliert. 